\title{
A natureza conservadora das pulsões sexuais: um olhar para além da meta ligadora de $\operatorname{Eros}^{1}$ \\ The conservative nature of sexual drives: a look beyond the binding aim of Eros
}

\section{Munique Gaio Filla*}

Resumo: Em 1920, Freud explicita que as pulsões apresentam uma natureza conservadora, já que tendem a retornar a estados anteriores, o que por vezes é visto como uma redefinição do conceito de pulsão em sua teoria. Se isso é ponto pacífico no campo das pulsões de morte, para as pulsões de vida e sua meta de ligar a substância viva em unidades cada vez maiores, é motivo de hesitação, ao ponto do psicanalista chegar a negar a possibilidade de que Eros seja conservador. O presente artigo objetiva analisar esta dificuldade aparente e mostrar que as pulsões sexuais, pertencentes ao grupo das pulsões de vida, sempre foram conservadoras para Freud. Assim, pretende questionar que haja propriamente uma redefinição da noção de pulsão e levantar um problema mais profundo o fato das pulsões sexuais almejarem retornar a estados menos ligados da vida libidinal e, com isso, esbarrarem na meta de Eros.

Palavras-chave: Pulsões de vida; Pulsões sexuais; Natureza conservadora; Ligação

Abstract: In 1920, Freud explains that the drives have a conservative nature, since they tend to return to previous states, which is sometimes seen as a redefinition of the concept of drive in his theory. If this is a peaceful point in the field of death drives, for life drives and its aim of binding living substance in ever larger units, it is a reason for hesitation, to the point that the psychoanalyst even denies the possibility that Eros is conservative. This article aims to analyze this apparent difficulty and show that sexual drives, belonging to the group of life drives, have always been conservative for Freud. Thus, it intends to question whether there is properly a redefinition of the notion of drive and raise a deeper problem - the fact that sexual drives crave to return to less bound states of libidinal life and, thus, bump into the aim of Eros.

Keywords: Life drives; Sexual drives; Conservative nature; Binding

\footnotetext{
${ }^{1}$ Este artigo se tornou possível pelo apoio institucional e financeiro da FAPESP (Fundação de Amparo à Pesquisa do Estado de São Paulo), processo 2018/09039-0.
}

* Estudante de Doutorado pelo Programa de Pós-Graduação em Filosofia da Universidade Federal de São Carlos, São Carlos, SP E-mail: muniquegf@gmail.com ORCID: https://orcid.org/0000-0001-7767-4968 


\section{Apresentação do problema: entre o aparente e o profundo}

"Mas desculpe-me se no que segue conto, como se fosse algo novo, coisas que todos sabem e admitem; é a coerência que me obriga a isso"2 - talvez esta seja a melhor maneira de iniciar mais um dos incontáveis esforços de investigar a doutrina das pulsões e suas especificidades na teoria freudiana. Seja pela característica indispensável do tema a qualquer um que se proponha a enveredar pela psicanálise, seja pela dificuldade em apreendê-lo, relativa à própria fronteira na qual se localiza, entre o corpo e a alma, entre o inconsciente e sua parca tradução consciente, sujeita a tantas insuficiências, trata-se de um objeto de estudo que não cessa de espicaçar nossas capacidades de reflexão. Isso nos condiciona a repetir muito do que já se conhece, motivo pelo qual tomo emprestadas aquelas palavras de Freud, em uma das tantas ocasiões em que se preocupa com o seu leitor e torna mais leve a densidade de seus conceitos. No entanto, ao mesmo tempo, não deixa de revelar novas possibilidades de leitura, que demonstram a fecundidade de voltar, quantas vezes for preciso, ao texto do pai da psicanálise. Como também ele mesmo afirma, é possível assegurar aos analistas que "por várias décadas seu trabalho científico não corre o perigo de se mecanizar e assim perder interesse"3, afinal flerta com as regiões mais obscuras da vida anímica, onde se situam as pulsões, a serem iluminadas gradativa e laboriosamente.

No que diz respeito ao segundo dualismo pulsional, sabe-se que teve uma lenta digestão nos círculos psicanalíticos, que ainda se faz presente; por vezes, foi simplesmente cuspido, ou engolido pela metade. Não tenho aqui a pretensão de defendê-lo, ou de mostrar a pertinência da ideia de pulsão de morte, algo que alguns autores já fizeram com maestria ${ }^{4}$. Interessa-me partir "de uma aparente redefinição do próprio conceito de pulsão"5 que estaria em jogo a partir da publicação de Além do princípio de prazer, de acordo com a expressão de Safatle. De "representação psíquica de uma fonte endossomática de excitação constante"6, a pulsão passaria a ser concebida desde o ponto de vista de sua natureza conservadora, conforme atesta a famosa sentença freudiana:

Uma pulsão seria então uma pressão (Drang), inerente ao orgânico vivo, de reprodução de um estado anterior ao qual o vivo precisou renunciar sob a

\footnotetext{
${ }^{2}$ FREUD, ¿Por qué la guerra?, p. 188; Warum Krieg?, p. 14.

${ }^{3}$ FREUD, Algunas consecuencias psíquicas de la diferencia anatómica entre los sexos, p. 267; Einige psychische Folgen des anatomischen Geschlechtsunterschieds, p. 19.

${ }^{4}$ Não posso deixar de citar Monzani, a título de exemplo, no terceiro capítulo de Freud: o movimento de um pensamento (p. 143-232).

${ }^{5}$ SAFATLE, A teoria das pulsões como ontologia negativa, p. 161.

${ }^{6}$ SAFATLE, A teoria das pulsões como ontologia negativa, p. 161.
} 
influência de forças perturbadoras externas; seria um tipo de elasticidade orgânica ou, se se quer, a exteriorização da inércia na vida orgânica ${ }^{7}$.

A pulsão de morte parece se harmonizar sem grandes empecilhos com essa suposta redefinição, afinal a ideia de que o Trieb consiste no ímpeto a retornar a estados mais antigos, já atravessados da vida anímica, é compatível com a meta desse grupo de pulsões de retornar ao estado inanimado, o que, por sua vez, também se ajusta aos argumentos freudianos de que o inorgânico precede o orgânico e de que a vida seria suscitada por forças perturbadoras externas e não internas. Já as pulsões de vida - aquelas que não causaram tanta polêmica entre os leitores de Freud, por significarem um rearranjo da categoria antes ocupada pelas pulsões sexuais, a fim de abarcar tanto as pulsões de objeto, quanto as pulsões do Eu narcisistas que têm como energia a libido - parecem não se conformar tão rapidamente a esse caráter conservador. Freud, por vezes, assume não estar certo de que Eros possa ser incluído nesta compreensão das pulsões, chegando ao ponto de recusar-lhe este caráter e considerá-lo uma exceção a esse respeito. Por terem como objetivo a união da substância viva em conjuntos cada vez maiores, a que estado de fusão precedente elas buscariam retornar? Os momentos em que Freud consegue sustentar a natureza conservadora das pulsões sexuais ou pulsões de vida se resumem às referências ao mito platônico do ser andrógino, presente na origem da vida, no qual os gêneros masculino e feminino estariam conjugados, hipótese à qual Freud admite aderir com reservas.

Tendo em vista este quadro, pretendo propor neste artigo que esse questionamento ou recusa de Freud sobre a adequação das pulsões de vida, Eros ou pulsões sexuais à natureza conservadora admitida no conceito de pulsão parece consistir em um problema aparente ou ilusório, que esconde um impasse teórico mais profundo. Para tanto, buscarei expor que não é difícil perceber como as pulsões sexuais compartilham desse caráter conservador, tanto em textos prévios, quanto posteriores à reformulação da doutrina das pulsões, no sentido de apresentarem a tendência a retornar a estados anteriores do desenvolvimento libidinal. Através da noção de inércia psíquica, viscosidade ou adesividade da libido, Freud já apontava para a resistência da última em abandonar posições e organizações já estabelecidas. Da mesma forma, noções como as de fixação, regressão e repressão, descobertas no campo das neuroses e transponíveis para o funcionamento psíquico de todos os indivíduos, também revelavam este traço da sexualidade. A ideia de que neuróticos e não neuróticos se lançam em uma busca incessante de recuperar a inalcançável primeira experiência de satisfação seria mais um indício disso.

O problema propriamente dito, então, não seria tanto o da compatibilidade entre os movimentos da pulsão sexual e a inclinação a repetir estados já vivenciados, mas sim o fato de que os estados aos quais ela retorna não condizem com o objetivo que Freud atribui a

${ }^{7}$ FREUD, Mas allá del princípio del placer, p. 36; Jenseits des Lustprinzips, p. 38. 
Eros, de transformar o múltiplo em uno, de reunir e ligar, uma vez que refletem organizações parciais da pulsão, próprias da sexualidade infantil. O que quero dizer com isso é que o movimento regressivo da pulsão sexual, perceptível nos textos freudianos, parece não se afinar à meta das pulsões de vida, e este seria efetivamente o impasse teórico. A sexualidade frequentemente abandonaria o estágio genital - cuja meta, a reprodução ou a fusão de células germinais, seria compatível com a finalidade de Eros -, alcançado de modo frágil e incompleto, rumo a modos de satisfação menos totalizantes.

Deste modo, pretendo desenvolver os argumentos na direção de defender que, consequentemente, a redefinição do conceito de pulsão apresentada em 1920 também parece ser apenas aparente. Um diagnóstico mais preciso revela que pelo menos a noção de pulsão sexual não era estranha às ideias correlatas de inércia, conservação, repetição ou retorno, que passam a compor explicitamente a concepção de pulsão a partir das reformulações teóricas dos anos 20. O impasse maior consistiria em admitir que as pulsões sexuais, incluídas na categoria da pulsão de vida, têm como única meta ligar e reunir - o que leva Freud a suspeitar da natureza conservadora de Eros. No limite, tal objetivo da pulsão sexual se consuma apenas na reprodução, o que contradiz toda a construção freudiana anterior sobre o curso da libido, sobre a coexistência da sexualidade infantil, parcial e pré-genital com a sexualidade adulta, sempre alcançada de modo inacabado, e o eterno incômodo decorrente dessa diferença, tão particular à criatura humana.

\section{A definição das pulsões segundo sua natureza conservadora e as reservas de Freud quanto a Eros}

No que tange à referida afirmação de Safatle, é possível constatar que a primeira descrição de pulsão à qual ele está se referindo consiste na definição canônica oferecida por Freud no artigo metapsicológico sobre as pulsões de 1915, ainda no contexto da luta entre pulsões sexuais e pulsões de autoconservação, "um conceito-limite entre o anímico e o somático" ou "um representante (Repräsentant) psíquico dos estímulos que provém do interior do corpo e alcançam a alma"8 - exigência à qual a alma está fadada por sua conexão com o corpo. A redefinição nomeada pelo filósofo seria decorrente da contraposição entre essa ideia e a noção explicitamente apresentada por Freud em Além do princípio de prazer, justamente aquela que fala sobre a natureza conservadora (konservativ Natur) das pulsões. "Da primeira à segunda definição, acrescenta-se um certo caráter teleológico que orienta a direção da pressão pulsional para as vias de uma operação de retorno"9, diz o autor. Para iniciar a discussão proposta e justificar que a ideia de

${ }^{8}$ FREUD, Pulsiones y destinos de pulsión, p. 117; Triebe und Triebschicksale, p. 214.

${ }^{9}$ SAFATLE, A teoria das pulsóes como ontologia negativa, p. 161 (grifos do autor). 
redefinição pode ser colocada em questão ${ }^{10}$, vejamos com mais detalhes como é exposta essa característica regressiva da pulsão. Tanto na sinuosa obra que comemora seu centenário, quanto em outras publicações de 1920 em diante, nos debrucemos sobre esse caráter da pulsão e sobre a posição de hesitação ou negação de Freud em relação à inclusão de Eros nesta descrição.

Em mais de uma ocasião - no artigo intitulado Psicanálise, de 1926, e no Compêndio de psicanálise, publicado em 1940, por exemplo -, ao tentar traçar uma espécie de histórico de sua doutrina das pulsões, Freud ressalta que estas consistem em forças (Kräfte) oriundas do corpo ou, em outras palavras, impostas por este, que se expressam psiquicamente em confronto desde o princípio da vida, através de representações afetivamente investidas - o que não parece trazer nada de novo, já que reitera o lugar do corpo como indispensável ao tratar da pulsão ${ }^{11}$. Também oferece ao leitor quase que uma conciliação entre a primeira teoria pulsional e a segunda, ao considerar que Eros simplesmente passou a abarcar as pulsões de conservação de si mesmo e da espécie (Selbsterhaltungs- und Arterhaltungstriebe), bem como o amor do Eu e o amor de objeto todos os impulsos libidinais -, com a "novidade"12 de que se opõem agora às silenciosas, mas poderosas, pulsões de morte ${ }^{13}$. Em 1923, em O Eu e o Isso, o próprio autor nos autoriza a tratar como equivalentes os termos pulsões de vida, Eros e pulsões sexuais, desde que entre as últimas também contém moções pulsionais sublimadas ou de meta inibida e as de autoconservação, atribuídas ao Eu, que desde o narcisismo revelaram, pelo menos em

\footnotetext{
${ }^{10}$ Vale notar que a ideia de redefinição do conceito de pulsão sob um ponto de vista semelhante também aparece nas palavras de Silva Junior, em um texto bastante atual, A pulsão de morte e sua crueldade sem álibi: "Em Além do princípio de prazer, o autor [Freud] redefine o que entende por pulsão: se até então ela era pensada como uma tensão interna do corpo sobre o psiquismo, tensão da qual o psiquismo não poderia fugir, ela passa a ser pensada como 'uma tentativa de retorno a uma situação anterior inerente a todo organismo'" (p. 15, grifos meus).

${ }^{11} \mathrm{~A}$ propósito, fato que, por si só, já poderia nos levar a uma desconfiança quanto à redefinição do conceito de pulsão a partir de 1920.

${ }^{12}$ Sabemos, afinal, que não é algo exatamente novo - a ideia de que o aparelho psíquico almeja, em última instância, escoar todas as tensões que recebe e voltar ao estado zero de estímulos está presente, ainda que em outros termos, desde o Projeto de psicologia, escrito em 1895. É um dos aspectos que Monzani mostra em sua análise do segundo dualismo pulsional, no já citado Freud, o movimento de um pensamento. Desconfiar das leituras de Freud a partir de rupturas ou continuidades e atentar para os movimentos de seu pensamento, para o fato de que os problemas aparecem ora com mais ênfase, ora com menos protagonismo; ora sob um ângulo, ora sob outro ponto de vista, sem que sejam propriamente abandonados ou inventados, de uma hora para outra, é um ensinamento de Monzani que não deve ser esquecido. Aliás, é uma orientação desse tipo que guia o presente trabalho no que diz respeito ao problema específico levantado no campo das pulsões, conforme espero demonstrar no prosseguimento do texto.

${ }^{13}$ FREUD, Psicoanálisis, p. 253; Psychoanalyse, p. 301-302/ Esquema del psicoanálisis, p. 146; Abriss der Psychoanalyse, p. 70.
} 
parte, sua natureza libidinal ${ }^{14}$. Por outro lado, no Compêndio, Freud também se ocupa daquela característica das pulsões que é especialmente interessante para os propósitos deste artigo:

Ainda que causa última de atividade, são de natureza conservadora; de todo estado alcançado por um ser brota um empenho de reproduzir esse estado tão logo tenha sido abandonado ${ }^{15}$.

Nesse ponto, é possível notar tanto as marcas da concepção de pulsão presente no texto metapsicológico de 1915 - "Toda pulsão é um fragmento de atividade"16 -, quanto daquela explicitamente apresentada em Além do princípio de prazer - do esforço ou ímpeto por reproduzir um estado já vivido, assim que o indivíduo se vê obrigado a superálo. Por um lado, Freud afirma que foi em Além... que se deu conta, pela primeira vez, da compulsão de repetição (Wiederholungszwang) e do caráter conservador da vida pulsional ${ }^{17}$. Por outro lado, em determinadas passagens do próprio texto de 1920 , o psicanalista já dá indícios ao leitor de que a natureza conservadora das pulsões não consiste em algo novo, nunca antes percebido pelas investigações psicanalíticas. Depois de buscar argumentos para sustentar a tese da compulsão de repetição, no quinto capítulo do livro Freud se pergunta: qual seria a relação entre esta e o pulsional (Triebhafte)? Ao que se segue a seguinte resposta, que antecede a menção à natureza conservadora das pulsões:

Aqui se nos impõe a ideia de que estamos sobre a pista de um caráter geral das pulsões - não reconhecido com claridade até agora, ou ao menos não destacado expressamente - e talvez da vida orgânica em gera ${ }^{18}$.

Quer dizer, o caráter regressivo da pulsão não consistiria em uma descoberta propriamente dita, mas resultaria de uma mudança de postura - olhar com lunetas o que até agora havia passado de certa forma despercebido. Na mesma página, encontra-se ainda uma nota de rodapé: "Não duvido que conjecturas semelhantes acerca da natureza das pulsões já tenham sido formuladas repetidas vezes"19. Advertências como essas aparecem lado a lado com comentários de Freud, ainda na mesma página, sobre o tom estranho dessa afirmação, visto que até então era comum enxergar na pulsão apenas o ímpeto à mudança. Ora, se não é o mesmo Freud que chama a atenção para a originalidade dessas supostas descobertas, quem também nos alerta para o fato de que não são tão surpreendentes assim, embora não tenham sido enfatizadas como deveriam - elemento que corrobora a dúvida de

\footnotetext{
${ }^{14}$ FREUD, El yo y el ello, p. 41; Das Ich und das Es, p. 269.

${ }^{15}$ FREUD, Esquema del psicoanálisis, p. 146; Abriss der Psychoanalyse, p. 70.

${ }^{16}$ FREUD, Pulsiones y destinos de pulsión, p. 117-118; Triebe und Triebschicksale,p. 214.

${ }^{17}$ FREUD, El malestar en la cultura, p. 114; Das Unbehagen in der Kultur, p. 477.

${ }^{18}$ FREUD, Mas allá del princípio de placer, p. 36; Jenseits des Lustprinzips, p. 38 (grifos meus).

${ }^{19}$ FREUD, Mas allá del princípio de placer, p. 36; Jenseits des Lustprinzips, p. 38.
} 
que esteja em jogo, de fato, uma redefinição do conceito de pulsão no que se entende por "virada" de 1920 na psicanálise freudiana.

A fim de prosseguir com essa discussão, proponho que nos voltemos agora para a posição assumida por Freud em relação às pulsões de vida, no que tange à natureza conservadora das pulsões. Já sabemos que a pulsão de morte não oferece resistências a se ajustar a esta concepção. Como já foi afirmado nos primeiros parágrafos deste artigo, Freud supõe que o inorgânico precede o orgânico e que a meta das pulsões de morte seria tão somente repetir essa situação que já existiu e que foi perturbada por forças desconhecidas e externas - retornar ao estado zero de tensão, ao estado inanimado. Também já vimos que Freud aponta, de modo ambíguo, aquele caráter da pulsão como inédito e, simultaneamente, indica que se trata de algo já vislumbrado na teoria psicanalítica. A ambiguidade também parece marcar presença nas considerações sobre as pulsões sexuais ou de vida, que por vezes são consideradas como passíveis de se adequar a essa definição, e por vezes não o são. Para expor essa posição freudiana, comecemos pela hesitação que ele demonstra abertamente em uma nota de rodapé acrescentada em 1925 a Além..., na ocasião do texto na qual ele se propõe a seguir até as últimas consequências a hipótese de que "todas as pulsões querem reproduzir algo anterior": "Não se esqueça que na sequência desenvolvemos uma argumentação extrema, a qual encontrará restrição e emenda quando se levam em conta as pulsões sexuais"20. Isso significa que o próprio Freud adiciona uma ressalva, alguns anos depois, acerca da argumentação por ele articulada nas páginas seguintes - a defesa de que as pulsões sexuais não só seriam conservadoras (konservativ), como o seriam em uma medida ainda maior do que as pulsões de autoconservação, anteriormente discutidas no escrito e compreendidas como asseguradoras de que o indivíduo morre à sua própria maneira. Por vigiarem as células germinativas, aquelas que sobrevivem ao indivíduo, mantê-las vivas, garantirem seu encontro ou sua fusão com outras células germinativas, as pulsões sexuais conservariam (erhalten) a vida por mais tempo e promoveriam uma espécie de imortalidade ${ }^{21}$.

\footnotetext{
${ }^{20} \mathrm{FREUD}$, Mas allá del principio de placer, p. 37; Jenseits des Lustprinzips, p. 39 (grifos meus).

${ }^{21}$ Nota-se que Freud considera as pulsões em seu caráter conservador pelo adjetivo konservativ, mas também pela ação de conservar, designada pelo verbo erhalten. Gostaria de chamar a atenção para o fato de a ideia de conservação parecer apontar para pelo menos dois sentidos diferentes: a tendência das pulsões a reproduzir (wiederherstellen) um estado anterior, revelada pela compulsão de repetição (Wiederholungszwang), e a inclinação a manter ou preservar a vida - sentido ligado ao verbo erhalten, que já era utilizado por Freud para caracterizar as pulsões de autoconservação (Selbsterhaltungstriebe), justamente aquelas que lutam pela preservação da própria vida, ou para falar da conservação da espécie (Arterhaltung) incluída nos desígnios das pulsões sexuais. A última noção parece se harmonizar com a meta das pulsões de vida de manter a união da substância viva ou mesmo de buscar a reunião das células germinativas. É o sentido de reprodução (Wiederherstellung) ou de retorno (Rückkehr), relacionado principalmente ao adjetivo konservativ, destacado a partir de 1920, que parece causar mais incômodo em relação às pulsões de vida - ponto que é particularmente relevante para o presente artigo.
} 
Por alguma razão, Freud se vê obrigado a adicionar ressalvas a essa suposta natureza conservadora de Eros, como atesta essa nota de 1925 e como também mostra a seguinte pergunta por ele escrita adiante no mesmo texto - "Na verdade não haverá, com exceção das pulsões sexuais, outras pulsões além das que pretendem restabelecer um estado anterior?"22. A resposta é negativa, já que o psicanalista diz não conhecer pulsões que tendam ao progresso evolutivo nos reinos animal e vegetal. De todo modo, de acordo com essa apóstrofe, podemos observar que a afirmação de Freud a respeito da natureza conservadora das pulsões de vida se dá de forma hesitante, uma vez que ele ressalta sua capacidade de conservar a vida com base na sua participação na fusão própria à reprodução e, simultaneamente, concebe-as como exceção à regra da natureza conservadora das pulsões. De fato, a questão fica repleta de ambiguidades ao longo do texto, ao ponto de Freud afirmar, no sexto capítulo:

Mas seguimos sentindo como um notável obstáculo para nossa argumentação que não podemos pesquisar, justamente a respeito da pulsão sexual, aquele caráter de compulsão de repetição que nos colocou sobre a pista das pulsões de morte ${ }^{23}$.

Assim, para não abrir mão da natureza regressiva das pulsões de vida, que colocaria em xeque suas hipóteses, e sustentá-la em concordância com a meta de fundir as células germinativas através da reprodução sexual, Freud se vê obrigado a supor um acontecimento anterior que seria reproduzido por tal união. Como não é possível localizar na ciência algo que explique essa gênese da sexualidade, tal como o papel que a precedência do estado inanimado ao animado cumpre em relação às pulsões de morte, recorre a uma hipótese situada em outro campo - o da mitologia. O psicanalista justifica que só comete a ousadia de tal recurso porque ele permitirá preencher essa insistente lacuna do texto - "Não me atreveria (wagen) a mencioná-lo se não preenchesse uma condição cujo cumprimento desejamos"24 -, a qual o fez incorrer naquelas tantas ambiguidades que foram pontuadas, entre ora afirmar a natureza conservadora das pulsões de vida ou pulsões sexuais; ora dizer que elas se encontram à parte e não podem ser incluídas nesta descrição. Trata-se da conhecida referência ao Banquete de Platão - o "filósofo poeta" (Dichterphilosoph) - e à ideia presente não só na obra dele, mas também em escrituras hindus ainda mais antigas, de que, a princípio, a humanidade se dividiria em três gêneros, a saber, macho, fêmea e andrógino. O último reuniria os outros dois e também apresentaria todas as partes do corpo duplicadas, até que Zeus teria ordenado a divisão do andrógino em duas partes, de modo que essas duas metades almejariam se

\footnotetext{
${ }^{22}$ FREUD, Mas allá del principio de placer, p. 41; Jenseits des Lustprinzips, p. 43 (grifos do autor).

${ }^{23}$ FREUD, Mas allá del principio de placer, p. 54; Jenseits des Lustprinzips, p. 60.

${ }^{24}$ FREUD, Mas allá del principio de placer, p. 56; Jenseits des Lustprinzips, p. 62.
} 
fundir novamente em um único ser. É a este estado que as pulsões sexuais buscariam retornar ${ }^{25}$.

No entanto, Freud não parece estar convencido de que o apoio nessa teoria platônica tenha resolvido seus problemas, conforme demonstram algumas passagens de obras posteriores. Em uma nota de rodapé à exposição da doutrina das pulsões em $O$ mal estar na cultura (1930), nos oferece uma sinopse das dificuldades que ele mesmo enfrenta a esse respeito:

É chamativa, e pode converter-se em ponto de partida de ulteriores indagações, a oposição que deste modo surge entre a tendência de Eros à expansão incessante e a universal natureza conservadora das pulsões ${ }^{26}$.

Chega, portanto, a falar de uma oposição (Gegensatz) entre o objetivo das pulsões de vida e o caráter regressivo das pulsões, além de insinuar a fecundidade da questão para investigações futuras - ensejo para a escrita de um artigo como este que se apresenta. A contradição gira em torno da incompatibilidade da meta atribuída àquela categoria de pulsões com o retorno a um estado anterior. Do mesmo modo, o seguinte trecho da $32^{\mathrm{a}}$ das Novas conferências de introdução à psicanálise, datada de 1933, pode nos conduzir a conclusões análogas:

As pulsões não regem só a vida anímica, mas também a vegetativa, e essas pulsões orgânicas mostram um traço que merece nosso maior interesse (que se trate de um caráter geral das pulsões, é algo que só mais tarde poderemos julgar): se revelam como empenhos por reproduzir um estado anterior. Cabe supor que no momento mesmo em que um desses estados sofre uma perturbação, nasce uma pulsão a recriá-lo e produz fenômenos que podemos designar como compulsão de repetição ${ }^{27}$.

Levando em conta que, ainda na mesma conferência, Freud repete que não há resposta sobre se todas as pulsões têm uma natureza regressiva, pelo fato de não ser possível saber "se também as pulsões eróticas querem restaurar um estado anterior toda vez que aspiram à síntese do vivo em unidades maiores" ${ }^{28}$, não há dúvidas de que o psicanalista continua deixando a questão em suspenso, apesar do apelo à mitologia realizado em 1920. Por fim, tal questão passa de pendente a resolvida no Compêndio, só que em favor da impossibilidade de que Eros seja conservador: "[...] não podemos aplicar a Eros (ou pulsão de amor) essa fórmula. Isso pressuporia que a substância viva foi outrora

\footnotetext{
${ }^{25}$ FREUD, Mas allá del principio de placer, p. 56-57; Jenseits des Lustprinzips, p. 62-63.

${ }^{26} \mathrm{FREUD}$, El malestar en la cultura, p. 114; Das Unbehagen in der Kultur, p. 477.

${ }^{27}$ FREUD, Nuevas conferencias de introducción al psicoanálisis, p. 98; Neue Folge der Vorlesungen zur Einführung in die Psychoanalyse, p. 113 (primeiros grifos meus, segundo grifo do autor).

${ }^{28}$ FREUD, Nuevas conferencias de introducción al psicoanálisis, p. 100; Neue Folge der Vorlesungen zur Einführung in die Psychoanalyse, p. 115.
} 
uma unidade depois rompida e que agora aspira à sua reunificação" ${ }^{29}$, mesmo que haja em seguida uma nota de rodapé relembrando que "os poetas fantasiaram algo semelhante", que, no entanto, não é conhecido pela ciência.

Com isso, nota-se que nosso autor admite a hipótese mitológica para se referir à existência de uma tendência ao retorno e à repetição nas pulsões de vida em Além..., como um ato de ousadia ou atrevimento plausível diante da necessidade de suprir lacunas na argumentação. Já em $O$ mal estar na cultura e na Conferência 32 volta a considerar a questão como não solucionada para, finalmente, em seu último grande escrito, posicionar o argumento platônico como não suficiente. Talvez isso se explique por um traço típico de sua obra, para o qual Monzani chama a atenção: "[...] a estratégia de Freud parece ser a de que o argumento singular, por si só, nada prova, só adquirindo valor quando se insere numa série. É a série, enquanto tal, que tem valor probatório"30. No que diz respeito às pulsões de vida, sexuais ou Eros, assistimos Freud se debater com o impasse de como poderiam ser conservadoras, se buscam a reunião e a ligação de partículas da substância viva, uma vez que isso requereria um estado primeiro de síntese. É justamente o último que o psicanalista só consegue ilustrar a partir do ser andrógino do mito platônico, o qual, tomado isoladamente, e não em conjunto com outros fenômenos nos quais pudesse ser observado, não tem valor de prova.

Diante do percurso até agora traçado, foi possível constatar que a adequação das pulsões de vida ao caráter conservador das pulsões não é, de modo algum, ponto pacífico na teoria freudiana. Também foi questionado o quanto esse caráter foi, de fato, introduzido em 1920, de acordo com as próprias insinuações de Freud, o que levaria a uma desconfiança de que o conceito de pulsão tenha sido redefinido com o segundo dualismo pulsional, justamente por adquirir a finalidade do retorno a estados anteriores, conforme apontava Safatle. O próximo passo será, então, o de argumentar que Freud parece preterir boa parte de sua própria teoria sobre a sexualidade quando opera com as seguintes equivalências - pulsões de vida ou Eros e pulsões sexuais, meta de fusão da substância viva ou, consequentemente, de reprodução, e inadequação disso com a característica das pulsões de buscarem sempre retornar ou recriar os estados recém abandonados. Propõe-se apontar para a característica de viscosidade ou adesividade da libido, energia psíquica da pulsão sexual, e para a centralidade das noções de fixação, regressão e repressão quando se fala em pulsão sexual na teoria freudiana. Com isso, buscarei tomar partido daquele posicionamento aberto pelo próprio Freud segundo o qual, na verdade, o caráter conservador das pulsões não se trata de uma inovação, o que pode significar que não tenha ocorrido uma redefinição do conceito no sentido estrito. A pulsão sexual, desde muito cedo em seu pensamento, se aproximou da ideia de conservação, como veremos a seguir, o que nos fornecerá a chave para situar o problema em outros termos - a sexualidade não parece

${ }^{29}$ FREUD, Esquema del psicoanálisis, p. 146-147; Abriss der Psychoanalyse, p. 71.

${ }^{30}$ MONZANI, Freud: o movimento de um pensamento, p. 155 (grifo do autor). 
se esgotar à meta abarcadora e sintética de Eros, justamente por ter uma natureza regressiva e movimentar-se rumo a organizações parciais do desenvolvimento.

\section{O aspecto regressivo das pulsões sexuais e suas consequências}

Já em 1905, nos Três ensaios sobre teoria sexual, Freud se propõe a pesquisar os fatores que podem perturbar o desenvolvimento das pulsões sexuais rumo à complexa "composição" (Zusammensetzung) própria da sexualidade adulta, na qual há o domínio da zona erógena genital e da função reprodutiva, em detrimento à sexualidade infantil, tão conhecida pelos adjetivos perversa e polimorfa, por conta da pluralidade de pulsões sexuais parciais e de zonas erógenas que a qualificam. Entre tais fatores, é significativo que nosso autor situe a "adesividade" (Harftbarkeit) ou "fixabilidade" (Fixierbarkeit) da libido, que deveria ser atribuída aos neuróticos e perversos, já que neles exteriorizações da vida sexual infantil parecem imprimir marcas de forma especialmente duradoura, ao ponto de provocar sua "repetição compulsiva" (zwangartig auf Wiederholung hinwirken) e prescrever, por toda a vida, os caminhos da pulsão sexual ${ }^{31}$. Desta forma, os neuróticos e perversos revelariam uma tendência desse tipo de pulsão a se fixar em determinado ponto do desenvolvimento e a repeti-lo, o que, por sua vez, justificaria as manifestações patológicas. Nesse sentido, muitos anos antes de reconhecer oficialmente a compulsão de repetição, Freud parecia identificar os germes desse fenômeno no campo da própria pulsão sexual - a qual, no entanto, mostra aquela resistência a se encaixar no ímpeto ao retorno que passa a ser explicitamente típico das pulsões em 1920, conforme já vimos.

Se investigarmos mais a fundo, podemos encontrar ideias semelhantes em diversos outros escritos, que atravessam toda a obra do criador da psicanálise. Podemos exemplificar tanto com um texto intermediário como Luto e melancolia, publicado em 1917, onde nos deparamos com a sentença de Freud - "[...] observa-se geralmente que o homem não abandona de bom grado uma posição libidinal, nem mesmo quando seu substituto já acena"32, quanto com um escrito da fase final, onde é possível ler a expressão "viscosidade" (Klebrigkeit) da libido, entendida como obstáculo encontrado em algumas pessoas durante o tratamento analítico, conforme a seguinte passagem de Análise finita $e$ infinita:

Os processos que a cura inicia nelas transcorrem muito mais lentamente que em outras, porque, segundo parece, não podem decidir-se a desfazer investimentos libidinais de um objeto e deslocá-los a um novo, ainda que

\footnotetext{
${ }^{31}$ FREUD, Tres ensayos de teoría sexual, p. 221; Drei Abhandlungen zur Sexualtheorie, p. 144. ${ }^{32}$ FREUD, Duelo y melancolía, p. 242; Trauer und Melancholie, p. 430.
} 
não se encontrem razões particulares para tal fidelidade aos investimentos ${ }^{33}$.

A possibilidade indicada acima, de que o indivíduo se fixe em determinadas posições libidinais, ainda que não tenha motivos para isso e mesmo que novos objetos e modos de satisfação se anunciem, vem junto da alusão a uma "inércia psíquica" enquanto dificuldade de modificar relações e distribuições da energia psíquica. Tal expressão também se repete no já citado Compêndio de psicanálise, desta vez através ao lado da menção a um certo "peso do movimento" (Schwerbeweglichkeit) da libido, que não quer abandonar suas fixações ${ }^{34}$, o que nos coloca na pista de uma inércia da própria libido, à qual Freud chega a fazer referência no Mal estar na cultura ${ }^{35}$.

A noção de inércia, portanto, tão presente na concepção de pulsão apresentada em Além..., em conexão com a compulsão de repetição, também parece se fazer presente desde muito cedo no pensamento freudiano. Em uma publicação de 1915 intitulada Um caso de paranoia que contradiz a teoria psicanalítica, Freud atribui a Jung a tese de que a inércia psíquica seria uma condição fundamental para a neurose e a explica com as seguintes palavras: "[...] ela se revela como a exteriorização de enlaces, estabelecidos precocemente e muito difíceis de desatar, de pulsões com impressões e com os objetos dados nestas" ${ }^{36}$. É por conta desses enlaces que os componentes pulsionais estagnam seu desenvolvimento; trata-se de uma expressão diferente para a fixação, já explorada pela psicanálise, segundo nosso autor. De fato, não é difícil recordar que a concepção de Freud sobre a neurose sempre circulou em torno dos conceitos de fixação e regressão, que estabelecem relações de dependência um com o outro. Seja por razões constitucionais, seja por obstáculos à satisfação que se impõem acidentalmente, a pulsão sexual frequentemente é frustrada em sua meta de satisfação e tende a retornar a etapas anteriores do desenvolvimento quando isso acontece. Regride justamente aos pontos onde componentes pulsionais ficaram fixados. Quanto mais fixações a pulsão sexual apresenta em seu trajeto, mais facilitada se encontra a via de retorno quando se faz necessário recuar. $\mathrm{Na} 22^{\underline{a}}$ das Conferências de introdução à psicanálise, publicada em 1916, Freud concede uma analogia esclarecedora desse movimento libidinal, ao compará-lo com um povo em migração que deixou parte de seu bando para trás enquanto caminhava. Esse povo que continuou a avançar não hesitará em retroceder caso se depare com um inimigo poderoso ou perca uma batalha, ao mesmo tempo em que as chances disso acontecer se mostram maiores quanto mais indivíduos tiverem sido abandonados ${ }^{37}$. A repressão também se enlaça com a fixação e a regressão, na

\footnotetext{
${ }^{33}$ FREUD, Análisis terminable y interminable, p. 243; Die endliche und die unendliche Analyse, p. 87.

${ }^{34}$ FREUD, Esquema del psicoanálisis, p. 182; Abriss der Psychoanalyse, p. 107-108.

${ }^{35}$ FREUD, El malestar en la cultura, p. 105; Das Unbehagen in der Kultur, p. 467.

${ }^{36}$ FREUD, Un caso de paranoia que contradice la teoría psicoanalítica, p. 271; Mitteilung eines der psychoanalytischen Theorie widersprechenden Falles von Paranoia, p. 246.

${ }^{37}$ FREUD, Conferencias de introducción al psicoanálisis, p. 310-311; Vorlesungen zur Einführung in die
} 
medida em que o Eu, ao lançar mão desse tipo de defesa contra a pulsão sexual, a empurra para estágios prévios do desenvolvimento libidinal ou, em outras palavras, promove a regressão a pontos de fixação, o que explica porque Freud tenha se esforçado em assinalar que certos tipos de neurose dependiam da existência de certos tipos de fixação, como os paranoicos, por exemplo, que provavelmente apresentavam a fase do narcisismo como ponto fraco de sua história psicossexual.

Neste quadro, cumpre um papel fundamental a concepção esboçada por Freud a respeito do próprio desenvolvimento da libido. A despeito de, em alguns momentos, parecer colocar uma espécie de ponto de chegada à pulsão sexual - a sexualidade adulta e normal, que se concentraria nos genitais e buscaria a reprodução, algo que é marcante no terceiro dos Três ensaios..., por exemplo, em sua tentativa de dar conta das mudanças advindas com a puberdade -, é possível refutar a hipótese de que o psicanalista tenha estabelecido esse telos para a sexualidade, como se a função sexual adulta determinasse, de antemão, o sentido do desenvolvimento sexual e fosse, portanto, sua norma ou seu fim. Limongi ${ }^{38}$, em sua dissertação de mestrado, apresenta um excelente exemplo desse tipo de refutação, ao fazer uma análise minuciosa do conceito de pulsão anterior a 1920. A autora aborda os ensaios sobre a sexualidade em sua relação com Pulsões e seus destinos, pois considera que neste artigo Freud conquista um equilíbrio teórico até então ausente no que tange à pulsão. Se em 1905 Freud parece deixar em aberto a possibilidade de que a pulsão sexual siga um caminho pré-fixado rumo à tarefa biológica da reprodução, que determinaria se seu funcionamento seria normal ou patológico, com os acréscimos do artigo metapsicológico de 1915 parece ganhar corpo a ideia de que a norma e o fim da sexualidade adulta não estariam pré-figurados na pulsão, mas seriam erigidos ou construídos ao longo do próprio desenvolvimento, podendo ou não serem alcançados. $\mathrm{O}$ que quero dizer é que, em conformidade com a tese de Limongi, há diversos indícios nos textos freudianos de que a pulsão fracassa em chegar a essa conformação adulta e que, por vezes, a alcança de modo bastante incompleto e instável, o que corrobora a hipótese de que não só a pulsão sexual se fixa a modos de satisfação primários, como não chega a sair deles em alguns casos ou os repete com bastante facilidade em outros.

Isso fica bastante claro quando Freud escreve, no Compêndio de psicanálise: "A vida sexual inclui a função de ganho de prazer a partir de zonas do corpo, função que é posta a posteriori (nachträglich) a serviço da reprodução. É frequente que ambas as funções não cheguem a se sobrepor completamente" 39 . Ou ainda quando diz, um pouco mais

\section{Psychoanalyse, p. 352-353.}

${ }^{38}$ Ver LIMONGI, A pulsão e seu conceito na metapsicologia freudiana.

${ }^{39}$ FREUD, Esquema del psicoanálisis, p. 150-151; Abriss der Psychoanalyse, p. 75 (grifos meus). A respeito da noção de nachträglich e Nachträglichkeit, convém adicionar algumas observações. Essa concepção brota no solo da teoria da sedução, segundo a qual o trauma responsável pela eclosão da neurose era composto por dois tempos: experiências sexuais passivas da infância, na qual a criança era desprovida de sexualidade, e sua 
adiante no mesmo texto, que o processo de passagem da sexualidade infantil para a sexualidade adulta - interpolada pelo período de latência -, que significaria o alcance da fase genital, "nem sempre se consuma de modo impecável"40. É fundamental ter em vista que esse processo de transformação alcança um êxito parcial e nunca completo, na medida em que a organização genital é alcançada por parte das pulsões sexuais, já que outra parte delas segue fixada a objetos e metas pré-genitais, o que leva Freud a enfatizar a inclinação da libido a retroceder diante do menor empecilho à sua satisfação.

Se ficou alguma impressão de que esse quadro tem a ver com a neurose ou outros tipos de patologia, já que foi abordado em torno das noções de viscosidade da libido, fixação, regressão e repressão, isso não constitui um impedimento para que seja generalizado à vida psíquica de todos os indivíduos. Em primeiro lugar, porque Freud mesmo opera com a distinção de grau, e não de natureza, entre os processos patológicos e aqueles considerados normais - a patologia não passaria de exageros, de excessos diagnosticados no funcionamento regular da alma. Em segundo lugar, porque o psicanalista assume, com todas as letras, que "é difícil que exista um estado reconhecido como normal em que não se possa rastrear indícios de traços neuróticos"41. Em outras palavras, parte do pressuposto de que "todas as pessoas são mais ou menos neuróticas"42, o que tem a ver com o fato de Freud conceber não apenas o desenvolvimento da libido, mas da vida psíquica em geral, a partir da ideia de que estados mais precoces convivem junto a estados posteriores, de modo que toda organização psíquica apresenta pontos mais frágeis, os quais se fazem presentes, mesmo que já tenham sido atravessados, e passíveis de serem revividos ou repetidos.

Freud adverte seus leitores a esse respeito em muitas obras, como na $35^{\mathrm{a}}$ das Novas conferências..., quando afirma - "Vocês sabem quão difícil é que seja sepultado algo que uma vez adquiriu expressão psíquica"43. Em o Mal estar na cultura, também confirma que

recordação já na puberdade ou depois dela, momento em que a sexualidade já havia se desenvolvido, de modo que as cenas de sedução adquiriam significação sexual a posteriori. Embora Freud deixe de lado esse modelo de explicação da etiologia das neuroses, a ideia de que eventos da vida psíquica apresentam efeitos retardados decisivos mantém sua relevância. Segundo Hanns, há dois sentidos nessa tese, que por vezes são inseparáveis, a saber, tanto o de eventos reprimidos que permanecem no inconsciente e determinam sintomas bem mais tarde na vida do indivíduo, quanto o de retorno a eventos antigos acompanhado de sua ressignificação, diante de novas experiências ou de algum tipo de maturação biológica - "uma atuação simultânea de dois vetores" (HANNS, Dicionário comentado do alemão de Freud, p. 87). De acordo com os propósitos deste artigo, interessa-me sugerir que a sexualidade adulta pode ser concebida como um efeito $a$ posteriori da sexualidade infantil, no duplo sentido do termo - modos de satisfação infantis continuam a agir sobre o psiquismo, apesar de serem reprimidos, e, simultaneamente, são um lugar de retorno para as pulsões sexuais, o que, por sua vez, reforça o argumento pela defesa da natureza conservadora das pulsões sexuais.

${ }^{40}$ FREUD, Esquema del psicoanálisis, p. 153; Abriss der Psychoanalyse, p. 77.

${ }^{41}$ FREUD, Esquema del psicoanálisis, p. 183; Abriss der Psychoanalyse, p. 109.

${ }^{42}$ FREUD, Manuscrito inédito de 1931, p. 67.

${ }^{43}$ FREUD, Nuevas conferencias de introducción al psicoanálisis, p. 153; Neue Folge der Vorlesungen zur 
"no âmbito da alma, é frequente a conservação (Erhaltung) do primitivo junto ao que nasceu dele por transformação"44, ao ponto de recorrer à imagem arqueológica da cidade de Roma, que guarda seu passado histórico em suas próprias construções, para ilustrar o passado da alma que não apenas sobrevive, inabalável, na vida psíquica, como também exerce efeitos nela durante toda a existência do indivíduo - efeitos mais ou menos impactantes, a depender do indivíduo ser mais ou menos neurótico, para utilizar a expressão freudiana recentemente mencionada. Para observar esse caráter indestrutível dos processos anímicos do ponto de vista da libido, é pertinente retomar o artigo metapsicológico sobre as pulsões, mais precisamente a ocasião na qual os impulsos (Schübe) da vida pulsional são comparados com as sucessivas erupções de lava em um vulcão, na medida em que a erupção mais originária coexiste, imutável, junto às seguintes, assim como as primeiras manifestações da pulsão são preservadas ao lado das que a sucedem na vida pulsional ${ }^{45}$. Dito de outro modo, Freud entende que, no trajeto da pulsão sexual, a formação sexual definitiva conserva (erhalten) fases anteriores da libido junto às configurações posteriores ${ }^{46}$.

Já com as características da pulsão sexual levantadas até agora - sua adesividade ou viscosidade, provocadoras de uma repetição compulsiva; sua inércia a deixar determinadas posições; sua capacidade de conservação de fases mais precoces junto a organizações mais tardias; sua tendência à fixação, bem como à regressão e, consequentemente, à repetição de estados já experienciados, seja por obra da repressão, seja por frustrações de outra ordem -, poderíamos sinalizar que é estranho Freud ter encontrado tantas dificuldades em harmonizá-la com a natureza conservadora das pulsões. Afinal, por que uma pulsão que apresenta tal relutância em avançar no desenvolvimento, que quando o faz, não se transforma completamente, preserva seus modos de ser anteriores, e ainda os repete, não seria conservadora? No entanto, convém acrescentar mais uma ideia que parece fortalecer esta tese, a saber, a de que a sexualidade seria movida pela tentativa de retornar à primeira experiência de satisfação. Assim, nos aproximamos de um conjunto de fenômenos cujo arranjo forma uma série de valor probatório em relação à natureza conservadora das pulsões sexuais, daquele tipo de série que é familiar à estratégia argumentativa de Freud, de acordo com o que foi recuperado de Monzani mais acima.

Para tanto, retornemos a Além do princípio de prazer, a uma passagem do texto que já foi recuperada anteriormente. Trata-se de uma das ocasiões de defesa da natureza conservadora das pulsões sexuais, quando Freud assume que elas deveriam ser ainda mais

Einführung in die Psychoanalyse, p. 178.

${ }^{44}$ FREUD, El malestar en la cultura, p. 69; Das Unbehagen in der Kultur, p. 426.

${ }^{45}$ FREUD, Pulsiones y destinos de pulsión, p. 126; Triebe und Triebschicksale, p. 223.

${ }^{46}$ FREUD, Nuevas conferencias de introducción al psicoanálisis, p. 92; Neue Folge der Vorlesungen zur Einführung in die Psychoanalyse, p. 106 e FREUD, Análisis terminable y interminable, p. 231; Die endliche und die unendliche Analyse, p. 73. 
conservadoras que as pulsões de autoconservação por conservar a vida por mais tempo, afirmação à qual ele adiciona, em 1923, a seguinte nota de rodapé: "E apesar disso são o único que podemos aduzir a favor de uma tendência interna ao 'progresso' e ao desenvolvimento mais elevado!"47. Um pouco mais adiante, fica mais claro o que Freud quer dizer com essa nota. Apesar da posição ambígua assumida em relação a Eros, nosso autor se empenha em convencer seu leitor da não existência de nenhuma "pulsão de aperfeiçoamento" (Vervollkommnungstrieb) que almejaria um progresso evolutivo, na medida em que seria próprio à pulsão apresentar aquela natureza conservadora. A aparência de uma tendência interna ao progresso, da qual o homem teria tanta resistência em abrir mão, por significar também a renúncia à crença de que estaria nos rumos de sua transformação em "super-homem" (Übermensch), seria proporcionada pelas pulsões reprimidas, conforme aponta Freud:

A pulsão reprimida nunca pára de aspirar a sua satisfação plena, que consistiria na repetição de uma vivência primária de satisfação; todas as formações substitutivas e reativas, e todas as sublimações, são insuficientes para cancelar sua tensão persistente, e a diferença entre o prazer de satisfação encontrado e o pretendido engendra o fator pulsionante (das treibende Moment), que não admite aferrar-se a nenhuma das situações estabelecidas, mas sim que, nas palavras do poeta, 'impele, indominado, sempre adiante'. O caminho até atrás, até a satisfação plena, em geral é obstruído pelas resistências em virtude das quais as repressões se mantém em pé; e então não resta senão avançar pela direção do desenvolvimento ainda livre, embora sem perspectiva de poder finalizar o processo e alcançar a meta ${ }^{48}$.

Se lembrarmos que, em sua teorização, são as pulsões sexuais que, via de regra, sofrem os processos repressivos ${ }^{49}$, pelo incômodo que causam na vida psíquica, não será difícil perceber que Freud está falando, em última instância, das pulsões sexuais e da impressão que causam de impulsionar o homem rumo a estágios mais elevados, tal como

\footnotetext{
${ }^{47}$ FREUD, Más allá del principio del placer, p. 40; Jenseits des Lustprinzips, p. 43.

${ }^{48}$ FREUD, Más allá del principio del placer, p. 42; Jenseits des Lustprinzips, p. 44-45 (grifos meus).

${ }^{49} \mathrm{~A}$ esse respeito, nosso autor afirma que "não há objeção nenhuma contra o pressuposto de que qualquer tipo de exigência pulsional possa dar ocasião às mesmas repressões com suas consequências. No entanto, nossa observação nos mostra de maneira regular, até onde podemos apreciá-lo, que as excitações a que corresponde esse papel patógeno procedem de pulsões parciais da vida sexual" (FREUD, Esquema del psicoanálisis, p. 185-186; Abriss der Psychoanalyse, p. 112). Quer dizer que constata, pela experiência, que as pulsões sexuais desempenham um papel imprescindível na produção das neuroses, mas, ao mesmo tempo, não deixa fechada a possibilidade de que outras pulsões tenham participação nisso, problema que se agrava pelo fato de que "a maioria das aspirações da vida sexual não são de natureza puramente erótica", mas consistem em mesclas de pulsões sexuais e de destruição, conforme continua o psicanalista, em sua atuação conjunta na vida psíquica.
} 
mostrava aquela nota de rodapé de 1923. Acontece que tal impressão esconde, justamente, o ímpeto das pulsões reprimidas em repetir uma vivência primária de satisfação, aquela que se encontra mais atrás no desenvolvimento, e não mais a frente. As defesas das quais o Eu se mune - as formações reativas, os sintomas, as sublimações - conseguem, em alguma medida, bloquear esse retorno que a pulsão reprimida almeja consumar; não são suficientes para sufocá-la, mas sim para desviá-las rumo a satisfações parciais, o que compõe a ilusão dessa tendência interna ao progresso. De acordo com essas passagens de Além..., portanto, vemos que Freud reconhece que as pulsões reprimidas buscariam repetir uma vivência primária de satisfação, que esta seria a satisfação plena e que o prazer alcançado por outras vivências substitutas nunca se iguala ao prazer pretendido. No entanto, é justamente esse movimento em busca da satisfação que confere a aparência de que haveria uma pulsão de aperfeiçoamento nos indivíduos.

O mais interessante para os propósitos desta discussão é esse reconhecimento de que o motor ou fator pulsionante de uma pulsão sexual reprimida parece ser essa busca por uma satisfação já vivida - a satisfação por excelência, podemos dizer. Isso fica ainda mais chamativo quando se percebe que, na psicanálise freudiana, este parece ser um movimento da pulsão sexual em geral - a tentativa de repetir a primeira vivência de prazer, que marca toda a vida pulsional dos indivíduos. Um dos textos que podem justificar essa afirmação consiste na 20 das Conferências de introdução à psicanálise. Em sua exposição sobre a sexualidade infantil, o autor se volta à prática do sugar (ludeln ou lutschen), cuja análise é bastante conhecida pelos leitores de Freud, na medida em que se trata do exemplo através do qual é explorada a noção de apoio (Anlehnung) das pulsões sexuais sobre as funções de autoconservação, desde os Três ensaios.... Tal prática evidencia o prazer colateral obtido através do mamar no peito materno, com a estimulação da zona erógena da boca, que se soma ao cumprimento da necessidade alimentar, e, consequentemente, o nascimento da pulsão sexual como independente da consumação das necessidades vitais. Tendo isso em vista, passemos aos seguintes comentários de Freud:

Se o lactente pudesse se expressar, sem dúvida reconheceria que o ato de mamar no peito materno é de longe o mais importante em sua vida. E não andaria errado, pois com ele satisfaz ao mesmo tempo as duas grandes necessidades vitais. E depois nos inteiramos pela psicanálise, não sem surpresa, da enorme importância psíquica que este ato conserva durante toda a existência. O mamar no peito materno se torna o ponto de partida de toda a vida sexual, o modelo inalcançado (das unerreichte Vorbild) de toda satisfação sexual posterior, ao qual a fantasia costuma retornar (zurückkehren) em momentos de necessidade. Inclui o peito materno como primeiro objeto da pulsão sexual; não posso comunicar-lhes a representação da importância deste primeiro objeto para todo encontro de objeto (Objektfindung) posterior, nem dos profundos efeitos que, em suas 
mudanças e substituições, segue exercendo sobre os mais distantes âmbitos de nossa vida anímica ${ }^{50}$.

É significativo que Freud conceda tal relevância ao ato de mamar no peito da mãe, ao ponto de concebê-lo como experiência primária e dupla de satisfação. A um só tempo, a recepção de alimento cessa a necessidade das pulsões de autoconservação e a excitação da zona erógena da boca oferece um ganho de prazer que satisfaz as pulsões sexuais. Isso leva Freud a considerar o seio materno como o primeiro objeto das pulsões sexuais, aquele que imprime uma marca permanente nas relações objetais posteriores do indivíduo, e o ato de mamar como protótipo para a satisfação sexual. Uma experiência originária como essa não tem apenas o estatuto de paradigma para a vida sexual, como também se oferece como lugar de retorno à fantasia diante de exigências pulsionais, ainda que sob a rubrica da impossibilidade, já que se trata de um modelo inalcançado, conforme as palavras de Freud. A convergência com o que vimos - o quadro no qual as pulsões reprimidas são emolduradas em Além... - aponta para o quanto as pulsões sexuais não deixam de almejar uma satisfação já alcançada, porém perdida; para sua busca de reviver um estado já experienciado, porém irrecuperável.

A tese freudiana presente nos Três ensaios... - "O encontro de objeto é propriamente um reencontro (Wiederfindung)"51 - parece apontar, justamente, para esse movimento da pulsão sexual em direção ao retorno e à repetição, ainda que deva ser lido com a ressalva de que se trata de um reencontro impossível. De toda forma, o peso dessa concepção da pulsão sexual na teoria freudiana precisa ser levado em conta na discussão que foi proposta. Não é à toa que um autor como Jacques Lacan tenha notado sua centralidade, ao ponto de reforçá-la e radicalizá-la em sua interpretação da obra freudiana. Vale retomar aqui o quarto Seminário, ainda que brevemente e com o objetivo de explicitar o destaque concedido pelo psicanalista francês a essa dimensão repetitiva da pulsão sexual. Isso porque Lacan entende que é uma repetição que está em jogo - "repetição impossível" - e que se trata de uma operação movida pela tentativa de retorno, pelo desejo de voltar ao passado: "Uma nostalgia liga o sujeito ao objeto perdido, através da qual se exerce todo o esforço da busca", busca de "uma satisfação passada e ultrapassada"52.

Em vista do que foi exposto até agora, tem-se boas razões para desconfiar da hesitação ou recusa de Freud em conceber que as pulsões sexuais sejam conservadoras e estejam inclinadas a reproduzir estados já superados. O problema, em última instância, não parece ser exatamente este, mas sim dar conta de que, precisamente por serem conservadoras, tendem a retornar a estágios pré-genitais do desenvolvimento libidinal e, portanto, mais parciais - tanto em relação aos objetos, quanto aos modos de satisfação.

\footnotetext{
${ }^{50}$ FREUD, Conferencias de introducción al psicoanálisis, p. 287; Vorlesungen zur Einführung in die Psychoanalyse, p. 324-325 (grifos meus).

${ }^{51}$ FREUD, Tres ensayos de teoría sexual, p. 203; Drei Abhandlungen zur Sexualtheorie, p. 123.

${ }^{52}$ LACAN, O seminário, livro 4: a relação de objeto, p. 13.
} 
Isso significa que essa operação de retorno se consuma da sexualidade adulta, que é majoritariamente genital e guiada pela meta reprodutiva ${ }^{53}$, em direção a organizações que são próprias da sexualidade infantil, que funciona de modo mais anárquico, com múltiplas pulsões sexuais que buscam a satisfação de modo independente umas das outras, partem de zonas erógenas distintas, como a boca, o ânus ou qualquer outra região do corpo, e fazem uso de objetos também parciais - como o seio materno, no caso já citado da zona erógena bucal, ou mesmo partes do próprio corpo, quando funciona de maneira autoerótica.

Nesse sentido, como falar de uma redefinição da pulsão a partir de 1920, correlativa à introdução de uma natureza conservadora neste conceito? Me parece que as ideias de conservação, inércia, retorno e repetição não eram nem um pouco estranhas, pelo menos às pulsões sexuais, desde o início da teoria freudiana. Portanto, o grande inconveniente com o qual Freud teria de lidar não é o das pulsões sexuais não serem conservadoras. Na medida em que Eros é equiparado às pulsões sexuais, a questão mais profunda parece ser a seguinte: como conciliar a meta de reunir e ligar, de transformar o múltiplo em uno, própria às pulsões de vida, com essa natureza regressiva das pulsões sexuais, de conservar e repetir estados menos ligados ou menos totais? As pulsões sexuais constantemente deixam de se submeter aos genitais e à meta reprodutiva, o fazem de um jeito inacabado ou nem mesmo chegam a fazê-lo, ao mesmo tempo em que aquela configuração parece ser a única que se harmoniza verdadeiramente com os objetivos que Freud atribui a Eros.

Por outro lado, nem mesmo Freud parece se convencer que é possível submeter totalmente as pulsões sexuais à meta de buscar ligações cada vez maiores e mais complexas. Tanto por falar de todas as características já levantadas, ligadas à natureza conservadora das pulsões sexuais, mesmo em textos bem tardios de sua obra, quanto por admitir, também até o final de seus escritos, que o fato da sexualidade ser fonte essencial de conflito na vida psíquica está relacionado a sua manifestação em dois tempos sexualidade infantil e adulta, intercaladas pelo período de latência -, particular ao ser humano ${ }^{54}$. Além do rechaço da cultura à livre expressão das pulsões sexuais, cumpre um papel fundamental para a causação dos sintomas neuróticos a dupla configuração própria da vida sexual humana, ao ponto de Freud afirmar que esta "é uma das condições do privilégio humano de se tornar neurótico"55. O que significa que, na psicanálise freudiana, a diferença entre a sexualidade infantil e a adulta, entre modos pré-genitais e parciais de satisfação e uma meta reprodutiva com hegemonia da zona erógena genital, exerce efeitos permanentes na vida psíquica. O sexual infantil é sempre um caminho aberto para a pulsão, é sempre lugar de fixação possível. A regressão a esse estado que fica conservado é

\footnotetext{
${ }^{53}$ Não poderia deixar de utilizar "majoritariamente" nessa explanação, afinal já vimos que essa transição da infância para a vida adulta, em termos sexuais, nunca se dá de modo integral.

${ }^{54}$ FREUD, Esquema del psicoanálisis, p. 186; Abriss der Psychoanalyse, p. 113.

${ }^{55}$ FREUD, ¿Pueden los legos ejercer el análisis?, p. 197; Die Frage der Laienanalyse, p. 239.
} 
um dos destinos viáveis para a moção pulsional que não pôde continuar seu trajeto, como já vimos.

Deste modo, como abrigar todas as pulsões sexuais sob o objetivo de reunir e ligar unidades cada vez maiores, se é próprio da natureza humana que na sexualidade sobrevivam as organizações perversas e polimorfas da infância junto à conformação adulta, que busca propriamente a união pela reprodução? Ou ainda, como dizer que Eros, pulsões de vida ou pulsões sexuais, termos substituíveis na teoria freudiana, não podem ser conservadoras, depois do que foi exposto até aqui? Assim, não se trata propriamente de uma redefinição do conceito de pulsão dizer que ela é conservadora; o que parece ser novo e problemático é querer subsumir todas as manifestações da pulsão sexual à meta de síntese, que só parece se consumar efetivamente na reprodução. Conforme procurou-se explicitar, ao mesmo tempo em que Freud aponta para essas teses, ele mesmo fornece elementos suficientes para nuançá-las.

\section{Considerações finais}

Parece imprescindível que as pulsões sexuais não se reduzam ao propósito de alcançar uma união cada vez mais abrangente, o qual se harmoniza sobretudo com a meta reprodutiva da fase genital. É preciso recuperar as próprias teses freudianas para contemplar as organizações pré-genitais e, portanto, parciais que se preservam no desenvolvimento da libido e seguem sendo modos de exteriorização da sexualidade. Vale notar o quanto esse diagnóstico pode ser aproximado ao de Laplanche, no que diz respeito à seguinte denúncia sobre o segundo dualismo pulsional de Freud: "A sexualidade correu o risco de ser completamente açambarcada, correu-se o risco de não mais ver na sexualidade senão este aspecto ligado, investido, calmo, quiescente"56. O autor aponta para a importância de se reafirmar algo que parece ter se perdido, precisamente o aspecto não tão ligado da sexualidade. Para Laplanche, trata-se de recuperar "a sexualidade tendo apenas um único fim que é o de correr o mais rápido possível para a satisfação e para a diminuição completa de seu desejo pelas vias mais curtas" 57 . No entanto, apesar da semelhança das conclusões, há diferenças consideráveis em relação às teses aqui defendidas e às de Laplanche, visíveis se lembrarmos, por exemplo, das interpretações específicas do autor, da qual não compartilho, de que há um monismo energético - só existe a energia da libido - e uma dualidade interna às pulsões sexuais, que seriam as únicas pulsões e se dividiriam entre pulsões sexuais de vida, aquelas que buscam "a síntese, a manutenção ou a constituição de unidades e de laços", e as pulsões sexuais de morte, cujo "fim é a descarga

\footnotetext{
${ }^{56} \mathrm{LAPLANCHE}$, A pulsão de morte na teoria da pulsão sexual, p. 20.

${ }^{57} \mathrm{LAPLANCHE}$, A pulsão de morte na teoria da pulsão sexual, p. 20.
} 
pulsional total, ao preço do aniquilamento do objeto"58 ou, em outras palavras, o desligamento ${ }^{59}$.

Por que retomar Laplanche agora? Pode perguntar-se o leitor. Ora, a fim de apontar que se leitores perspicazes de Freud como ele já indicaram a importância de não se perder de vista que a sexualidade não se resume ao objetivo de síntese, por outro lado, não consideraram certas particularidades para as quais apontam os argumentos aqui levantados. Procurou-se defender que as pulsões sexuais apresentam uma natureza conservadora e, por conseguinte, que é difícil assumir uma redefinição do conceito de pulsão a partir de 1920, o que nos aproximou dessa insuficiência, denunciada também por Laplanche, de que a sexualidade seja somente aquilo que busca ligar cada vez mais e mais a substância viva. Para isso, foram retomadas as noções de viscosidade ou adesividade da libido, de fixação, regressão e repressão e seu movimento de buscar repetir as primeiras vivências de satisfação. Esses argumentos, contudo, não parecem apontar para uma tendência da pulsão sexual ao desligamento propriamente dito, à supressão do objeto, como defende Laplanche, para quem o objeto parcial visado pelas pulsões sexuais de morte "mal é um objeto", ao passo que o objeto das pulsões sexuais de vida seriam, estes sim, objetos "em via ou em ato de totalização"60. Por mais que as pulsões sexuais se fixem ou regridam a estados anteriores e parciais do desenvolvimento, essas posições que elas ocupam implicam ainda em ligações. Não se trata propriamente de um aniquilamento do objeto ou necessariamente de uma expressão pura do desligamento. Há ligações a objetos, a modos de satisfação que, no entanto, são menos totais, menos sintéticos. Por essa razão, trata-se ainda de pulsões de vida.

Não tenho a intenção de, a essa altura, criticar a teoria de Laplanche, mas de convocá-lo para ressaltar um ponto com o qual esta discussão foi iniciada - por mais que estejamos fadados a nos repetirmos ao falar de pulsão no pensamento de Freud, há sempre mais a dizer e um ponto de vista distinto a explorar -, a fim de encerrar este trajeto com o prenúncio de novas possibilidades de investigação, e não com a retomada do que já foi exposto. O que quero dizer é que se o psicanalista francês já apresentou um diagnóstico que se assemelha àquele que foi defendido neste artigo, em contrapartida aloca a sexualidade em seu aspecto parcial sob a rubrica da morte e do desligamento, quando, na

${ }^{58}$ LAPLANCHE, A pulsão de morte na teoria da pulsão sexual, p. 22.

${ }^{59}$ Não cabe aqui justificar tal discordância - o que seria material para outro trabalho -, mas apenas fornecer indicações: embora não tenha nomeado outro tipo de energia que fosse específico das pulsões de morte, Freud não abriu mão de considerar a libido como energia própria das pulsões de vida; tampouco renunciou ao dualismo pulsional, na medida em que defende que ambas são pulsões primordiais, em ação conjunta desde as origens da vida, já que quase nunca aparecem em sua expressão pura e funcionam, sobretudo, em misturas com diferentes proporções (Ver, por exemplo, FREUD, Más allá del principio del placer, p. 59; Jenseits des Lustprinzips, p. 66; FREUD, Análisis terminable y interminable, p. 248; Die endliche und die unendliche Analyse, p. 92).

${ }^{60}$ LAPLANCHE, Novos fundamentos para a psicanálise, p. 155-156. 
verdade, é possível enxergar na repetição à qual incorrem as pulsões sexuais uma busca por modos mais antigos de satisfação, que embora sejam parciais, continuam implicando em ligações, evidentemente menos complexas e totalizantes. Não é à toa que, em trechos já citados, Freud descreva aquela dificuldade da libido em abandonar certas posições como uma "fidelidade aos investimentos" ou a partir da impossibilidade de desatar "enlaces" que a pulsão estabelece com certas impressões e com os objetos dados nelas. $\mathrm{O}$ fato de que as pulsões sexuais insistam nessas ligações precoces e parciais, retornem a elas e as repitam faz com que não seja possível subsumi-las completamente aos propósitos de síntese que Freud estabelece para as pulsões de vida, mas não significa que deixem de expressar intenções das últimas. Não será o caso de alargar o conceito de pulsões de vida, para a busca de ligações, tanto aquelas mais sintéticas, quanto aquelas menos totais, ao invés de estreitar a sexualidade à meta reprodutiva de união ou de deslocar a parcialidade das pulsões sexuais para o domínio da morte? Que o trabalho infindável do psicanalista continue operando para encontrar as respostas.

\section{Referências}

FREUD, S. Tres ensayos de teoría sexual (1905). In: FREUD, S. Obras completas, v. 7. Trad. José Luiz Etcheverry. Buenos Aires: Amorrortu Editores, 1992./ Drei Abhandlungen zur Sexualtheorie. In: FREUD, S. Gesammelte Werke, v. 5. Frankfurt am Main: S. Fischer Verlag, 1968.

FREUD, S. Pulsiones y destinos de pulsión (1915). In: FREUD, S. Obras completas, v. 14. Trad. José Luiz Etcheverry. Buenos Aires: Amorrortu Editores, 1992./ Triebe und Triebschiksale. In: FREUD, S. Gesammelte Werke, v. 10. Frankfurt am Main: S. Fischer Verlag, 1949.

FREUD, S. Un caso de paranoia que contradice la teoría psicoanalítica (1915). In: FREUD, S. Obras completas, v. 14. Trad. José Luiz Etcheverry. Buenos Aires: Amorrortu Editores, 1992./ Mitteilung eines der psychoanalytischen Theorie widersprechenden Falles von Paranoia. In: FREUD, S. Gesammelte Werke, v. 10. Frankfurt am Main: S. Fischer Verlag, 1949.

FREUD, S. Duelo y melancolía (1917). In: FREUD, S. Obras completas, v. 14. Trad. José Luiz Etcheverry. Buenos Aires: Amorrortu Editores, 1992./ Trauer und Melancholie. In: FREUD, S. Gesammelte Werke, v. 10. Frankfurt am Main: S. Fischer Verlag, 1949.

FREUD, S. Conferencias de introducción al psicoanálisis (1917). In: FREUD, S. Obras completas, v. 16. Trad. José Luiz Etcheverry. Buenos Aires: Amorrortu Editores, 1991./ Vorlesungen zur Einführung in die Psychoanalyse. In: FREUD, S. Gesammelte Werke, v. 11. Frankfurt am Main: S. Fischer Verlag, 1969. 
FREUD, S. Más allá del principio del placer (1920). In: FREUD, S. Obras completas, v. 18.

Trad. José Luiz Etcheverry. Buenos Aires: Amorrortu Editores, 1992./ Jenseits der Lustprinzips. In: FREUD, S. Gesammelte Werke, v. 13. Frankfurt am Main: S. Fischer Verlag, 1967.

FREUD, S. El yo y el ello (1923). In: FREUD, S. Obras completas, v. 19. Trad. José Luiz Etcheverry. Buenos Aires: Amorrortu Editores, 1992./ Das Ich und das Es. In: FREUD, S. Gesammelte Werke, v. 13. Frankfurt am Main: S. Fischer Verlag, 1967.

FREUD, S. Algunas consecuencias psíquicas de la diferencia anatómica entre los sexos (1925). In: FREUD, S. Obras completas, v. 19. Trad. José Luiz Etcheverry. Buenos Aires: Amorrortu Editores, 1992./ Einige psychische Folgen des anatomischen Geschlechtsunterschieds. In: FREUD, S. Gesammelte Werke, v. 14. Frankfurt am Main: S. Fischer Verlag, 1955.

FREUD, S. ¿Pueden los legos ejercer el análisis? (1926). In: FREUD, S. Obras completas, v. 20. Trad. José Luiz Etcheverry. Buenos Aires: Amorrortu Editores, 1992./ Die Frage der Laienanalyse. In: FREUD, S. Gesammelte Werke, v. 14. Frankfurt am Main: S. Fischer Verlag, 1955.

FREUD, S. Psicoanálisis (1926). In: FREUD, S. Obras completas, v. 20. Trad. José Luiz Etcheverry. Buenos Aires: Amorrortu Editores, 1992./ Psycho-Analysis. In: FREUD, S. Gesammelte Werke, v. 14. Frankfurt am Main: S. Fischer Verlag, 1955.

FREUD, S. El mal estar en la cultura (1930). In: FREUD, S. Obras completas, v. 21. Trad. José Luiz Etcheverry. Buenos Aires: Amorrortu Editores, 1992./ Das Unbehagen in der Kultur. In: FREUD, S. Gesammelte Werke, v. 14. Frankfurt am Main: S. Fischer Verlag, 1955.

FREUD, S. Nuevas conferencias de introducción al psicoanálisis (1933). In: FREUD, S. Obras completas, v. 22. Trad. José Luiz Etcheverry. Buenos Aires: Amorrortu Editores, 1991./ Neue Folge der Vorlesungen zur Einführung in die Psychoanalyse. In: FREUD, S. Gesammelte Werke, v. 15. Frankfurt am Main: S. Fischer Verlag, 1961.

FREUD, S. ¿Por qué la guerra? (1933). In: FREUD, S. Obras completas, v. 22. Trad. José Luiz Etcheverry. Buenos Aires: Amorrortu Editores, 1991./ Warum Krieg? In: FREUD, S. Gesammelte Werke, v. 16. Frankfurt am Main: S. Fischer Verlag, 1961.

FREUD, S. Análisis terminable y interminable (1937). In: FREUD, S. Obras completas, v. 23. Trad. José Luiz Etcheverry. Buenos Aires: Amorrortu Editores, 1991./ Die endliche und die unendliche Analyse. In: FREUD, S. Gesammelte Werke, v. 16. Frankfurt am Main: S. Fischer Verlag, 1961. 
FREUD, S. Esquema del psicoanálisis (1940). In: FREUD, S. Obras completas, v. 23. Trad. José Luiz Etcheverry. Buenos Aires: Amorrortu Editores, 1991./ Abriss der Psychoanalyse. In: FREUD, S. Gesammelte Werke, v. 17. Frankfurt am Main: S. Fischer Verlag, 1955.

FREUD, S. Manuscrito inédito de 1931. Trad. Elsa Vera Kunze Post Susemihl. São Paulo: Blucher, 2017.

HANNS, L. A. Dicionário comentado do alemão de Freud. Rio de Janeiro: Imago, 1996.

LACAN, J. O seminário, livro 4: a relação de objeto. Trad. Dulce Duque Estrada. Rio de Janeiro: Zahar, 1995.

LAPLANCHE, J. A pulsão de morte na teoria da pulsão sexual. In: GREEN, A. et al. $A$ pulsão de morte. Trad. Claudia Berliner. São Paulo: Editora Escuta, 1988. p. 11-27.

LAPLANCHE, J. Novos fundamentos para a psicanálise. Trad. Claudia Berliner. São Paulo: Martins Fontes, 1992.

LIMONGI, M. I. M. P. A pulsão e seu conceito na metapsicologia freudiana. 1994.

Dissertação (Mestrado em Filosofia) - Faculdade de Filosofia, Letras e Ciências Humanas, Universidade de São Paulo, São Paulo, 1994.

MONZANI, L. R. Freud: o movimento de um pensamento. 2 ed. Campinas: Editoria da UNICAMP, 1989.

SAFATLE, V. A teoria das pulsões como ontologia negativa. Discurso, São Paulo, n. 36, p. 148-189, 2007. Disponível em: http://www.revistas.usp.br/discurso/article/view/38076/40802 . Acesso em: Nov. 2019.

SILVA JUNIOR, N. da. A pulsão de morte e sua crueldade sem álibi. Revista Cult, São Paulo, ano 23, n. 256, abr. 2020. Dossiê Pulsão de morte, p. 15-18. 